\title{
A Case of Acute Myocarditis and Rhabdomyolysis after a Scorpion Sting
}

\author{
Süleyman Ersoy', Fevzi Yılmaz², Bedriye Müge Sönmez², Ali Yücel Kara³, Aydın Güçlü \\ 'Department of Emergency, Ahi Evran University Training and Research Hospital, Kırşehir, Turkey \\ 2Department of Emergency, Ankara Numune Training and Research Hospital, Ankara, Turkey \\ Department of Physiology, Erciyes University Graduate School of Health Sciences, Kayseri, Turkey \\ ${ }^{4}$ Department of Nephrology, Ahi Evran University Training and Research Hospital, Kırşehir, Turkey
}

\begin{abstract}
Introduction: Scorpion stings continue to be a current public health problem in tropical regions of the world. Local effects are usually seen, but fatal cardiovascular complications may occur, albeit rarely, from scorpion stings. The purpose of this case is to emphasize that rhabdomyolysis and myocarditis can occur in patients admitted to a hospital with a scorpion sting.

Case Report: A 30-year-old male patient presented to our emergency department (ED) with complaints of pain and redness in the bite site after being stung by a scorpion. His blood pressure was $180 / 100 \mathrm{mmHg}$ and heart rate was $130 /$ min. Electrocardiography (ECG) showed a sinus tachycardia. Laboratory tests revealed the following values: creatinine: 1.71 mg/dL, creatinin kinase (CK): $2129 \mathrm{U} / \mathrm{L}$, creatinin kinase-myocardial band (CK-MB): $43.24 \mathrm{ng} / \mathrm{mL}$, and troponin: $22.59 \mathrm{ng} / \mathrm{mL}$. After catheterization of the bladder, dark brown urine was seen. There were no pathological findings in coronary angiography, but the left ventricular ejection fraction was detected as $45 \%$. The clinically stable patient was discharged on the fifth day of hospitalization. There were no abnormal findings in the latest tests of laboratory parameters.

Conclusion: Scorpion stings can cause death due to toxic effects on the cardiovascular system. Observations for possible complications from a scorpion sting, such as the possibility of myocarditis, should be kept in mind in patients admitted to the ED with complaints of a scorpion sting.
\end{abstract}

Keywords: Scorpion sting, myocarditis, rhabdomyolysis

Received: 19.12.2015 Accepted: 08.04.2016 Available Online Date: 15.07.2016

\section{Introduction}

Scorpion stings continue to be a current public health problem in tropical and subtropical regions of the world. Although the exact incidence of scorpion stings is not known, it is estimated that the annual number of scorpion stings exceeds 1.2 million, with 2.3 billion people at risk worldwide. Scorpion stings are also important in Turkey because of the increased incidence in the eastern and southeastern regions of Anatolia (1). Local effects are usually seen, but fatal cardiovascular complications may occur, albeit rarely, from scorpion stings (2). The purpose of this case is to emphasize that rhabdomyolysis and myocarditis can occur in patients admitted to a hospital with a scorpion sting.

\section{Case Report}

A 30-year-old male farmer presented to our emergency department (ED) with complaints of pain and redness in the bite site approximately $1 \mathrm{~h}$ after being stung on his left foot by a scorpion while he was working on his farm in the night. The patient had no chronic diseases, medical drug use, or allergy in his medical history. He was discharged a few hours after his examination, treatment, and follow-up at the observation unit because all the symptoms were relieved after treatment and there were no abnormal values from the laboratory examinations. He was re-admitted to the ED with complaints of widespread body pain, fatigue, and mild shortness of breath approximately $6 \mathrm{~h}$ after his discharge. During his physical examination, he was conscious, cooperative, oriented, and also mildly agitated. His vital signs were blood pressure, 180/100 mmHg; heart rate, 130/min; tempera-

Address for Correspondence:

Süleyman Ersoy, Department of Emergency, Ahi Evran University Training and Research Hospital, Kırşehir, Turkey

E-mail: ersoydr@hotmail.com

oCopyright 2017 by Emergency Physicians Association of Turkey - Available online at www.jemcr.org 
ture, $36.5^{\circ} \mathrm{C}$; and oxygen saturation in room air, 96\%. Systemic evaluation was normal, except for a single bite mark on the dorsum of the left foot. The electrocardiogram (ECG) showed a sinus tachycardia (Figure 1). Initial laboratory tests revealed the following values: white blood cells (WBC): 15.000/mm33, creatinine: $1.22 \mathrm{mg} / \mathrm{dL}$, creatinin kinase (CK): $637 \mathrm{U} / \mathrm{L}$, creatinin kinase-myocardial band (CK-MB): 5.74 $\mathrm{ng} / \mathrm{mL}$, and troponin: $0<100 \mathrm{ng} / \mathrm{mL}$. In the second referral, increased levels of creatinine, CK, and CK-MB were detected (1.71, 2129, and 43.24, respectively). After catheterization of the bladder, dark brown urine was observed.

He was monitored and a normal saline infusion was started intravenously. In the eighteenth hour of his follow-up in the emergency observation unit, the levels of creatinine and CK decreased (1.14 and 1924, respectively), but the patient was admitted to the intensive care unit with a diagnosis of acute coronary syndrome and myocarditis due to significantly increased levels of CK-MB and troponin I (53.40 and 22.59, respectively).

There was no pathological finding in the coronary angiography, but the left ventricular ejection fraction (EF) was detected as $45 \%$. This was consistent with the mild left ventricular systolic dysfunction found from the ECG during further investigations. With the pre-diagnosis of acute coronary syndrome and acute myocarditis, $300 \mathrm{mg}$ acetylsalicylic acid (Dispril; Reckitt Benckiser, Slough, UK), 0.6 mL low molecular weight heparin, and nitroglycerin (Nitroglycerine; Abbott Laboratories, North Chicago, IL) were administered to the patient. However, $5 \mathrm{~mL}$ scorpion anti-venom (Anti-Scorpion Venom; Er-Em Pharma, İstanbul, Turkey) (it was diluted with $50 \mathrm{~mL}$ 0.9\% sodium chloride solution, 30 min. i.v infusion), 80 mg intravenous steroid, and $5 \mathrm{mg}$ antihistamines against allergic reactions due to the antivenom were administered for treatment. Significant improvement (EF 55\%) of the left ventricular EF was detected in the ECG performed on the third day. This situation was interpreted as an acute rapidly improved myocarditis related to the scorpion sting. The clinically stable patient was discharged after the recovery of laboratory tests on the fifth day after hospitalization with recommendations of a regular follow-up, medical treatment such as aspirin, ramipril, and carvedilol due to the risk of cardiomyopathy. Informed patient's consent form was obtained.

\section{Discussion}

Scorpion toxin is a water-soluble antigen complex containing a mixture of neurotoxin, cardiotoxin, nephrotoxin, hemolysine, phosphodiesterase, phospholipase, hyaluronidase, histamine, and other chemicals (3). The clinical signs depend on the dose of poison, patient age, season, and the time between scorpion bite and admittance to hospital (2). Although pain, heat, edema, and hematoma in $97 \%$ of all the cases were observed as local effects (1), systemic effects such as hypotension or hypertension, respiratory failure, cardiovascular toxicity, hemolysis, renal failure, and hemorrhaging can also be seen in $3 \%$ of all cases (2).

Systemic effects are mediated by the autonomic nervous system, and scorpion toxin causes catecholamine release from the adrenal

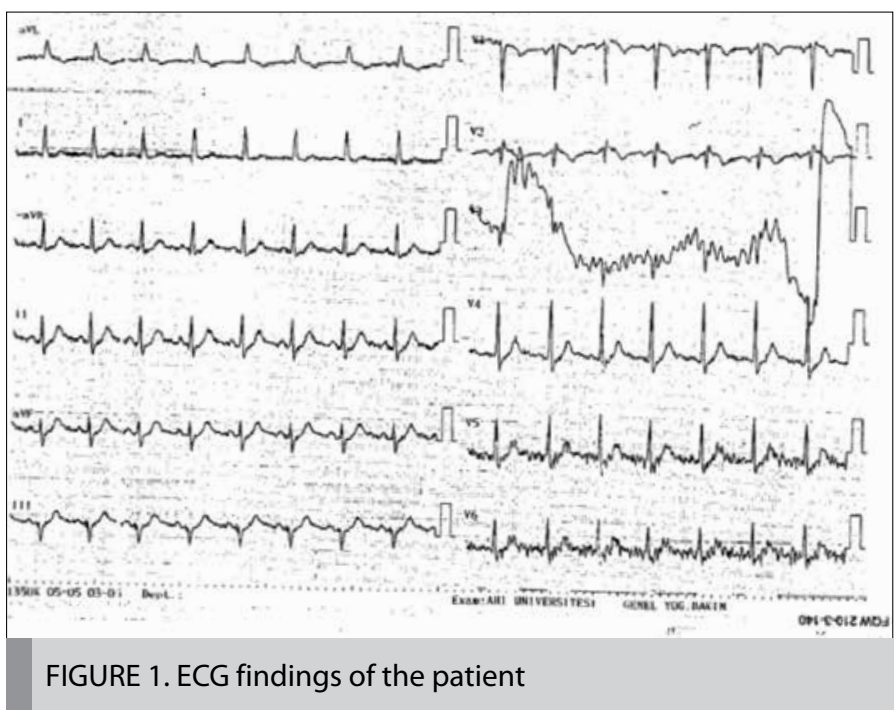

medulla by stimulating the sympathetic nerve endings. Because of the increased catecholamine discharge at an early stage, hypertension and increased left ventricular contraction may occur. In the late stage, biventricular systolic dysfunction, especially in the left ventricle, hypotension, pulmonary edema, and cardiogenic shock occur because of the catecholamine depletion syndrome and the quinine/prostaglandin activation pathway (4). Hypertension in mild cases and hypotension or pulmonary edema in severe cases of scorpion stings have been observed by Sofer et al. (5). Gueron et al. (6) showed that scorpion venom may cause tachycardia and hypertension. The hypertensive and tachycardic situation suggests that our case was at the early stages. We believe that early initiation of medical treatment could prevent the progression of acute heart failure.

The most common cause of death after a scorpion sting is due to cardiovascular complications. Increased catecholaminergic activity, decreased myocardial perfusion due to microvascular spasms, as well as direct toxic effects to the myocardium were responsible for the cardiovascular distress signs (7).

ECG findings associated to scorpion stings are usually non-specific. Recent studies have shown that there were ECG changes in 76\% cases, and commonly seen arrhythmias displayed a sinus tachycardia (8). Meki et al. (4) investigated the relationship between clinical courses and levels of troponin, and they have suggested that elevated levels of troponin $(4.73 \pm 0.76)$ were correlated with a poor clinical course. In our patient, the presence of elevated levels of troponin and left heart failure support this finding.

In patients with a scorpion sting, respiratory support should be provided first along with anti-venom. ECG and cardiac enzymes tests should be performed, especially in patients with a shortness of breath or impaired general status. If there is an imbalance of fluid and electrolyte or heart failure, treatment should be planned immediately. It has been reported that alpha-adrenergic blockers such as prazosin prevent heart damage related to increased catecholamine in the acute phase (9). This medical treatment improves the clinical findings in majority of patients in similar cases as this study. 
Most of the patients show clinical improvement in a short time. Even if the patients appear to be healed visually after a scorpion sting, subclinical damage can continue and it can lead to the development of cardiomyopathy over time (6). In our patient, although acute myocarditis and heart failure was treated medically within 48 $\mathrm{h}$ and ECG findings were improved, a regular follow-up is recommended for this reason.

Rhabdomyolysis is a syndrome that causes skeletal muscle damage with many causes. The classical triad contains myalgia, generalized weakness, and dark colored urine. Conner reported that rhabdomyolysis developed in $20 \%$ of cases after scorpion envenomation (10). Levels of CK were seen above $1000 \mathrm{IU} / \mathrm{L}$ in patients that developed rhabdomyolysis in the same study. Our case experienced fatigue, generalized muscle pain, dark colored urine, and an elevated level of CK (2129 IU/L). In patients that experienced fatigue and generalized muscle pain after a scorpion sting, rhabdomyolysis should be kept in mind. Anti-venom and fluid therapy should be administered rapidly.

\section{Conclusion}

Scorpion stings can cause death due to toxic effects on the cardiovascular system. Observations for possible complications from a scorpion sting and the possibility of myocarditis should be kept in mind in patients admitted to the ED with complaints of a scorpion sting, especially with shortness of breath and poor general conditions.

Informed Consent: Written informed consent was obtained from patient who participated in this case.

Peer-review: Externally peer-reviewed.

Author contributions: Concept - S.E.; Design - S.E., A.Y.K.; Supervision - S.E., B.M.S., F.Y.; Resource - S.E., A.G., A.Y.K.; Materials - S.E.; Data Collection\&/or
Processing - A.G., A.Y.K.; Analysis\&/or Interpretation - A.G., B.M.S.; Literature Search - F.Y.; Writing - B.M.S., F.Y.; Critical Reviews - S.E., A.Y.K.

Conflict of Interest: The authors declared no conflict of interest.

Financial Disclosure: The authors declared that this study has received no financial support.

\section{References}

1. Yılmaz F, Arslan ED, Demir A, Kavalcı C, Durdu T, Yılmaz MS, et al. epidemiologic and clinical characteristics and outcomes of scorpion sting in the southeastern region of Turkey. Ulus Travma Acil Cerrahi Derg 2013; 19: 417-22. [CrossRef]

2. Al B, Yılmaz DA, Söğut Ö, Orak M, Üstündağ M, Bokurt S. epidemiological, clinical characteristics and outcome of scorpion envenomation in Batman, Turkey: An analysis of 120 cases. JAEM 2009; 8: 9-14.

3. Bawaskar HS, Bawaskar PH. Scorpion sting: update. J Assoc Physicians India 2012; 60: 46-55.

4. Meki AR, Mohamed ZM, Mohey El-deen HM. Significance of assessment of serum cardiac troponin I and interleukin-8 in scorpion envenomed children. Toxicon 2003; 41: 129-37. [CrossRef]

5. Sofer S. Scorpion envenomation. Intensive Care Med 1995; 21: 626-8. [CrossRef]

6. Gueron M, Adolph RJ, Grupp IL, Gabel M, Grupp G, Fowler NO. Hemodynamic and myocardial consequences of scorpion venom. Am J Cardiol 1980; 45: 979-86. [CrossRef]

7. Cupo P, Figueiredo AB, Filho AP, Pintya AO, Tavares Júnior GA, Caligaris $F$, et al. Acute left ventricular dysfunction of severe scorpion envenomation is related to myocardial perfusion disturbance. Int J Cardiol 2007; 116: 98-106. [CrossRef]

8. Kumar CM, Prasad SV. Echocardiologic evaluation and follow-up of cardiovascular complications in children with scorpion sting in coastal South India. Indian J Crit Care Med 2015; 19: 42-6. [CrossRef]

9. Gupta BD, Parakh M, Purohit A. Management of scorpion sting: prazosin or dobutamine. J Trop Pediatr 2010; 56: 115-8. [CrossRef]

10. O'Connor A, Ruha AM. Clinical Course of Bark Scorpion Envenomation Managed without Antivenom. J Med Toxicol 2012; 8: 258-62. [CrossRef] 